\title{
O ENSINO DA DEONTOLOGIA NOS CURSOS DE GRADUAÇĀO MÉDICA DO BRASIL
}

\section{Evandro Guimarães de Souza * Flávio Dantas **}

\begin{abstract}
Resumo - Com a finalidade de obter subsídios relativos ao ensino da Deontologia , foi enviado questionário as 76 escolas de Medicina no Pals, a partir de dados contidos no Cadastro das Escolas Médicas, resultante do Prograina de Desenvolvimento de Recursos Humanos no Brasil (Acordo MEC/MS/MPAS/OPS).

$A$ análise dos dados obtidos permitiu concluir que o ensino da Deontologia deva ser ministrado durante todo o Curso Médico, através de debates entre alunos e professores, com prioridade para os docentes com vivência clínica, boa formação psicológica e cultura humanística. Os autores indicam o método de resolução de problemas como procedimento de escolha para a formação ética do aluno.
\end{abstract}

\section{Introdução}

A Resolução no 8, do Conselho Federal de Educação, de 8 de outubro de 1969, que fixa os mínimos de conteúdo e duração do Curso de Medicina, determina que Medicina Legal e Deontologia constituam matérias profissionais do currículo dos cursos de graduação em Medicina $^{1}$. A Resolução estipula, no artigo 10 , que as matérias do currículo mínimo devem ser organizadas em disciplinas e dispostas nos currículos plenos, de acordo com os planos de ensino de cada instituição, e se tem observado uma consistente aliança entre o ensino da Medicina Legal e da Deoritologia nas escolas médicas.

Dados do Cadastro das Escolas Médicas, referentes a 1981, indicam que 40 escolas oferecem a disciplina conjunta de Medicina Legal e Deontologia, com uma carga horária média de 30 horas. Por outro lado, enquanto 28 escolas incluem a disciplina de Medicina Legal, isoladamente, com carga horária média de 63 horas, em apenas 17 escolas, das quais 12 públicas, Deontologia é oferecida como disciplina autônoma, com uma carga horária média de 30 horas $^{2}$.

$\mathrm{Na}$ tentativa de identificar alguns aspectos ligados ao ensino da Deontologia, que pudessem

(*) Secretário Executivo da Comissão Nacional de Residência Médica, Ministério da Educação e Cultura

(* *) Professor, Departamento de Clínica Médica, Centro de Ciências Biomédicas, Universidade Federal de Úberiândia. servir de subsídio para uma análise mais aprofundada, os autores elaboraram um questionário, enviado para todas as escolas médicas.

\section{Métodos}

O instrumento constava de dois questionamentos básicos. Na primeira parte, solicitava-se a listagem das disciplinas relacionadas com a área de ética médica, acompanhadas de suas respectivas cargas horárias semestrais, ou anuais, número de professores e alunos e o ano, ou período, em que são ministradas. $\mathrm{Na}$ segunda parte, pediase a indicação do número de professores responsáveis pela disciplina, de acordo com sua área de especialização. Ao final, requeria-se o envio do plano de curso da(s) disciplina(s) relacionadas à área de ética médica, ministrada(s) pela instituição.

Os questionários foram enviados às 76 escolas de Medicina do País, através do seu Diretor, para que fossem respondidos pelos professores dessas disciplinas, dentro do prazo determinado de 30 dias. Após três tentativas de coletas de dados, foram obtidas respostas de 51 instituições, sendo 1 da Região Norte, 9 do Nordeste, 29 do Sudeste, 10 do Sul e 2 Centro-Oeste.

\section{Resultados}

Através da análise dos questionários enviados, verificou-se que, quando a disciplina de Deontologia é ministrada isoladamente, a carga horária total varia de 10 a 60 horas e, quando associada à Medicina Legal, de 45 a 140 horas.

Em 32 escolas, a disciplina possui 1 ou 2 professores para um número muito variável de alunos, não havendo diferença significativa entre as públicas e as da rede privada, mas, a menor proporção aluno/professor encontrada foi de $40 / 5$ e a maior foi de $113 / 1$.

Das 51 escolas médicas, apenas quatro (Universidade Federal de Uberlândia, PUC-Sorocaba, Universidade Federal de Juiz de Fora e Universidade Federal de Sergipe) não incluem legistas, ou patologistas, no corpo docente da disciplina. 
Por outro lado, apesar de $1 / 3$ das escolas médicas pesquisadas oferecerem a discip!ina de Deontologia, isoladamente, a responsabilidade de sua docência continuou com os legistas em $75 \%$ delas. Verificou-se, ainda, maior concentração do ensino da Deontologia no 80 e 9 ? períodos dos cursos (correspondentes ao 4 ? ano nas escolas com regime anual).

A análise qualitativa dos planos de curso, do ponto de vista do conteúdo ministrado, informa a predominância do enfoque de temas estreitamente vinculados à seqüência do antigo Código de Ética Médica. Assim, são privilegiados os seguintes temas: introdução à ética médica, responsabilidade profissional médica, segredo médico, honorários profissionais, relacionamento com o doente, relacionamento com colegas e entidades médicas, charlatanismo e curandeirismo e deveres fundamentais do médico.

\section{Comentários}

A formação ética dos futuros médicos é um problema que não parece ter sido analisado de forma efetiva pelas escolas médicas. Apesar de se concordar com a afirmativa de que "a instituição que ensina forma o profissional médico, mas é o mercado de trabalho que o conforma, reforma, ou deforma" ${ }^{\prime 3}$, torna-se clara a necessidade de repensar o ensino da Deontologia nas escolas, preocupadas, principalmente, com aspectos técnicos e informativos da ciência médica.

O ensino da ética médica, como disciplina isolada, tem sido contestado por alguns docentes, sob a incompleta alegação de que ética não se aprende, mas se apreende a partir dos exemplos dos docentes e supervisores médicos. Ou seja, como se a aprendizagem da ética médica envolvesse apenas aspectos afetivos, sem qualquer participação nas áreas cognitiva e mesmo psicomotora. Na realidade, esta reação parece traduzir a desinformação reinante na classe médica sobre aspectos éticos do exercício da Medicina, e suas conseqüências penais e criminais, reforçada pelo desinteresse de professores e médicos em conhecer os textos legais e documentos oficiais relacionados com o assunto.

Vivemos num mundo em constante evolução. A moral varia com o correr dos tempos, e estas transformações acarretam novas articulações e pensamentos no plano da ética. A falta de análise concreta destas mudanças pode levar a profissão médica, como parece estar acontecendo atualmente, a um aviltamento degradante, a uma competição acirrada, a uma luta pela sobrevivência, em que o alvo da atenção do médico, seguramente, não será o doente, "em benefício do qual deverá agir com o máximo de zelo e o melhor de sua capacidade profissional". 4 A disciplina de Deontologia deveria, pois, se constituir num centro aglutinador das inquietações existentes na esfera ética, divulgando e promovendo reuniões com a participação de docentes e alunos, para um debate franco e produtivo. Como disciplina isolada, tem-se constatado que muitas vezes adquire um tom paternalista, procurando ensinar os alunos a agir desta e daquela maneira, a partir da experiência dos mais velhos. Válida, não resta a menor dúvida, mas incompleta. Sem se tornar um pólo de discussão e debate, a partir dos valores pessoais e das experiências vividas por alunos e professores, alicerçados no conhecimento dos dispositivos legais aplicáveis a cada problema.

Uma estratégia que possibilita, concretamente, a realização de tais debates em salas de aula é o método de resolução de problemas, através da análise de casos reais. A partir da discussão destas situações mais comuns em relação aos diversos temas que devem ser debatidos na disciplina, os alunos tomam contato com os textos legais, correntes filosóficas e alternativas de solução de tais situações, que possivelmente serão vividas por eles num futuro próximo, ou algumas vezes já experimentadas durante o seu treinamento em serviço.

"O mais grave delito ético é a coisificação do doente, e isto não está codificado" ${ }^{5}$. O ensino da ética médica, portanto, deve-se constituir num momento de reflexão pessoal de cada um dos alunos, sobre seus valores, objetivos de vida, preceitos éticos e legais e a profissão que deverão exercer, com sua finalidade, direitos e deveres. Nesse sentido, impõe-se a necessidade de professores com vivência clínica, boa formação psicológica e cultura humanística.

A constatação de poucos livros-textos que possam ser úteis para o ensino da Deontologia apóia a conclusão de que parece haver uma apatia e desinteresse acentuados pela área de ética médica nas escolas de Medicina. Compreensível na medida em que status, elevada remuneração e prestígio profissional não estão diretamente associados aos profissionais de ensino e médicos preocupados prioritariamente com questões éticas. Mas inaceitável, na medida em que compete às escolas médicas orientar efetivamente a formação do médico, auxiliando-o a compreender o doente, seu núcleo familiar, e assim, obter uma real consciência crítica de sua participação junto à comunidade.

\footnotetext{
Summary - Aiming to get further information to improve the teaching of Deontology, a questionnaire was sent to all the 76 medical schools in the Country, based on data from the National Medical Schools List which resulted from the Development of Human Resources Programme in Brasil.

The analysis of the results led to the conclusion
} 
that the teaching of Deontology must be given during all the undergraduate course, through debates between teachers and students, with priority to teachers with clinical, psychological and humanistic background. The authors indicate the problem-solving method as the chosen procedure for the ethical education of the student.

\section{Referências bibliograficas}

1. BRASIL. Leis, decretos, etc. Resolução n? 8 de 8 de outubro de 1969 do Conselho Federal de Educação. In: ARAÚJO, L.S. org. Legislação do ensino superior; índice remissivo e jurisprudência. Rio de Janeiro, Renes, 1973.

2. BRASIL. Secretaria de Educação Superior. Cadas. tro de escolas médicas. Braś́lia, 1984. mimeo.
3. CHAVES, M. apud: LIBERATTI, L.A. A formação ética do médico e a atual estrutura de saúde. In: CONGRESSO BRASILEIRO DE EDUCAÇÃO MÉDICA, 16. Londrina, 22-24 nov. 1978. Anais. Londrina, ABEM, 1978. p. 117.

4. BRASIL. Leis, decretos, etc. Resolução n? 1.154, de 13 de abril de 1984. Diário Oficial da União, Brasília, 27 de abril de 1984. Código Brasileiro de Deontologia.

5. LOPES, J.L. A ética médica na formação do profissional de medicina. R. bras, Educ. Med., 4 (2): 45-52, maio/ago., 1980.

Endereço do autor:

SOS - 106 Bloco K apto 502

70345 - Braś́lia - DF 